\title{
Ecological niche modeling of the rare bee Promelitta alboclypeata reveals possible cryptic differentiation across northern Africa and Arabia (Hymenoptera: Melittidae)
}

\author{
Ismael A. Hinojosa-Díaz ${ }^{1}$, Abdulaziz S. AlqarnI ${ }^{2}$, Andrés LiRA-Noriega ${ }^{3}$, \\ Michael S. ENGEL ${ }^{4}$

\begin{abstract}
${ }^{1}$ Departamento de Zoología, Instituto de Biología, Universidad Nacional Autónoma de México, Tercer Circuito s/n, Ciudad Universitaria, Copilco, Coyoacán. A.P. 70-153, México, Distrito Federal 14510, Mexico

${ }^{2}$ Department of Plant Protection, College of Food and Agriculture Sciences, King Saud University, P.O. Box 2460, Riyadh 11451, Kingdom of Saudi Arabia

${ }^{3}$ Catedrático CONACyT, Red de Estudios Moleculares Avanzados, Instituto de Ecología, A.C., Carretera antigua a Coatepec 351, El Haya, Xalapa 91070 Veracruz, Mexico Kansas, 1501 Crestline Drive - Suite 140, Lawrence, KS 66045-4415, USA
\end{abstract} \\ ${ }^{4}$ Division of Entomology, Natural History Museum, and Department of Ecology \& Evolutionary Biology, University of
}

Received 27 February 2015 - Revised 9 July 2015 - Accepted 19 August 2015

\begin{abstract}
The scarcely collected bee Promelitta alboclypeata with known occurrence across northern Africa and the Arabian Peninsula is a typical example of the bee family Melittidae which encompasses a good number of species with sparse or disjunct distributions and particular flower preferences. Using records for 16 localities, we estimated ecological niche models for P. alboclypeata in Maxent on four sets of occurrences, to represent the disparity of the known records, most of them known from the western section of the range. Our estimates show a predicted area for the species in the northern section of the geographic extent assumed accessible to the species (mainly north Africa and the Arabian Peninsula), signaling feasible regions to survey for the presence of the species; possible ecological niche differentiation between the western and eastern populations is also signaled by the models.
\end{abstract}

\section{Melittidae / Promelitta alboclypeata / ecological niche models / ecological differentiation}

\section{INTRODUCTION}

Although bees (Apoidea: Anthophila) are among the most critical of wild pollinators in most terrestrial ecosystems worldwide (Michener 2007), for the vast majority of the approximately 20,000 known species, there are few data on their distribution, natural history, and ecology. Indeed,

Electronic supplementary material The online version of this article (doi:10.1007/s13592-015-0387-5) contains supplementary material, which is available to authorized users.

Corresponding author: I. Hinojosa-Díaz, hinojosadiaz@gmail.com

Manuscript editor: Klaus Hartfelder for most species, there are only handfuls of published occurrences, and though some may cover vast ranges, there are massive gaps between geographic localities and covering diverse landscapes with different floras and ecological settings. While many species revisions discuss subtle differences in morphological variation, there is no evidence for what kind of possibly ecological differentiation may exist within a species over a wide extent of geographic space. This is an important consideration as regional specialization may be an initial driving factor toward eventual population differentiation and speciation, or may contribute to the development of broad floral preferences within a species as populations at allopatric extremes adapt to local environmental situations, rather than 
speciation driven by host shifts which appears to be rare among bees (e.g., Sipes and Wolf 2001; Minckley and Roulston 2006).

Species of the bee family Melittidae are well known for their often narrow floral preferences, and many species are sparse or occupy disjunct distributions (Michener 2007) that may lead to eventual boundaries for populations to become specialized through synchronization to dominant regional resources (Minckley and Roulston 2006). For this reason, these bees may serve as an ideal test case for initial attempts to understand possible ecological differentiation across their distributions and promote further investigation into localized biologies at the extremes of their range. We attempt to explore some of these hypotheses through ecological niche modeling of the rare, solitary melittid bee, Promelitta alboclypeata (Friese) (Figure 1), in order to get a picture of the potential distribution of the species and finding any hints of ecological differentiation. Ecological niche modeling has previously been used to project distributions of bee species for which few or no data are known for specific areas

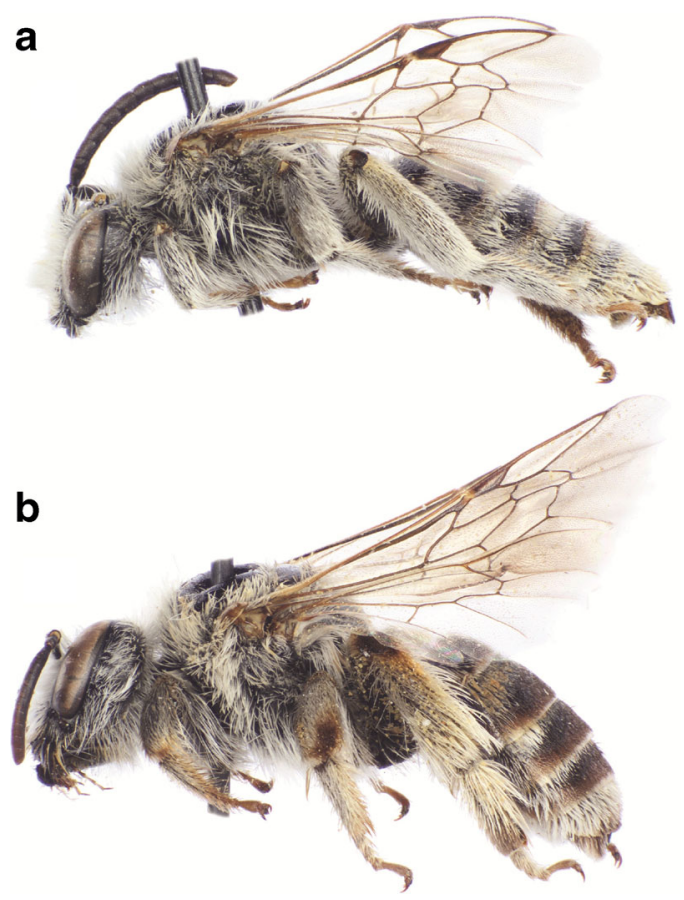

Figure 1. Lateral habitus of Promelitta alboclypeata (Friese) from Morocco, male (a) and female (b). (e.g., Hinojosa-Díaz et al. 2009; Gonzalez et al. 2010; Silva et al. 2013). P. alboclypeata occurs broadly across northern Africa and into Arabia (Michez et al. 2007; Dathe 2009) and has been considered the sole representative of the tribe Promelittini (Michener 1981; 2007; Engel 2005), although recent phylogenetic work has suggested it to be a primitive species of the tribe Macropidini (Michez et al. 2009). The species is a putative oligolege on Convolvulus, although pollen records are rare and its true floral ecology is unknown.

\section{MATERIALS AND METHODS}

Available occurrence points for P. alboclypeata were taken from Michez et al. (2007), who referred locality records with coordinates for 11 localities in Morocco and one locality in Sudan. Additional records with localities not cited by Michez et al. (2007) were taken from collection specimens as follows: one locality in Morocco from one specimen deposited in the Snow Entomological Collection, Division of Entomology, University of Kansas Natural History Museum, Lawrence, KS, USA (SEMC); one locality in Saudi Arabia from specimens deposited in SEMC and King Saud University Museum of Arthropods, Plant Protection Department, College of Food and Agriculture Sciences, King Saud University, Riyadh, Kingdom of Saudi Arabia (KSMA) (locality was reported by Engel et al. 2013); and two localities in the United Arab Emirates from Dathe (2009). Geographic coordinates for the records from Saudi Arabia were taken in situ by M.S. Engel, while those for the localities from the United Arab Emirates and the additional Moroccan locality from SEMC were obtained using GEOLocate (Rios and Bart 2010).

To characterize environmental variation, we used climatic layers from the WorldClim data archive (Hijmans et al. 2005; www.worldclim.org) at a spatial resolution of $10^{\prime}$. To avoid fitting models in overly dimensional environmental spaces, we reduced dimensionality to the first six principal components on standardized variables among 15 bioclimatic variables: annual mean temperature, mean diurnal range, isothermality, temperature seasonality, maximum temperature of warmest month, 
minimum temperature of coldest month, temperature annual range, mean temperature of warmest quarter, mean temperature of coldest quarter, annual precipitation, precipitation of wettest month, precipitation of driest month, precipitation seasonality, precipitation of wettest quarter, and precipitation of driest quarter. Principal components were generated in a geographic extent that included the occurrence points plus an area that was assumed accessible for the species given the type of terrestrial ecoregion (Olson et al. 2001) where the points fell.

Because the numbers of occurrences for the species are scarce and unevenly distributed across the geography, we estimated ecological niche models in Maxent (3.3.3.e; Phillips et al. 2006) on four sets of occurrences as follows. One niche estimate was done over all occurrences together; second and third estimates were done for all western (Morocco) and eastern (Sudan, Saudi Arabia, and UAE) sets of occurrences, respectively; and a fourth estimate was created for three geographically rarefied sets of points that included all occurrences in the east and an equal number of occurrences randomly selected from the west. In each case, models were estimated with the first six principal components of the environmental variables, which accounted for $99 \%$ of overall variance in the environmental dataset (see Online Resource). Models were calibrated via 10 crossvalidation replications, and given the potential uncertainty with occurrence points used subject to georeferencing errors, we applied two thresholds ( $E=5$ and $10 \%)$ over the median of the 10 replicates to convert models to binary predictions. The remaining Maxent parameters were left as default. In the case of the three models from the geographically balanced sets of occurrences, the final estimate corresponded to the area where the three models coincided. The predictive model performance in each binary was assessed with a jackknifing approach using the method presented in Pearson et al. (2007).

\section{RESULTS}

The binary predictions resulting from the four sets of occurrences as presented here (Figure 2) show estimates for P. alboclypeata to occur in the areas including the ecoregions used in the study. The estimates obtained with all the occurrences (Figure 2a, b), the rarefied set (Figure 2c, d), and the one including only the west occurrences (Figure 2e, f) are similar in that the predicted area for the species is in the northern section of the geographic extent used for the model for both Africa and the Arabian Peninsula, as well as sections of Iran, Afghanistan, Pakistan, and Turkmenistan. The set including all occurrences with a threshold of $5 \%$ (Figure 2a) gives the largest estimate of the three sets mentioned above and is similar to the estimate with only west occurrences at a $5 \%$ threshold (Figure 2e). The rarefied set with both thresholds (Figure 2c, d) and the set of west occurrences at a $10 \%$ threshold (Figure $2 \mathrm{f}$ ) give basically the same estimated area. The estimate produced, using the set including only the four occurrences in the east, shows an area for the most part complementary to the estimates produced with the other three sets, showing areas on the margins south within the geographic extent in the model, as well as narrow scattered sections along the Mediterranean Sea (Figure 2g, h).

Although all 16 occurrence points used in the analysis fell within an estimated area when considering all four sets, no individual estimate included all occurrence points within the predicted estimate. The most inclusive estimate was the one using all occurrences, only missing the locality on northeastern Sudan (Figure 2a and b). This particular location fell within the estimated area only in the estimates produced with the east occurrences (Figure 2g, h). The eastern localities (Sudan, Saudi Arabia, UAE) were within the estimate when those were the ones used in the analysis (Figure 2g, h); however, the Saudi locality was on the margin of the prediction, while with this same set, the southwestern most Moroccan locality was also within the estimate. This point was marginal in the rarefied estimates and the ones produced with the west occurrences.

\section{DISCUSSION}

The morphological and taxonomic features of P. alboclypeata make it an interesting case within the melittid bees, a group also known for their sparse or disjunct distributions, as well as for their 

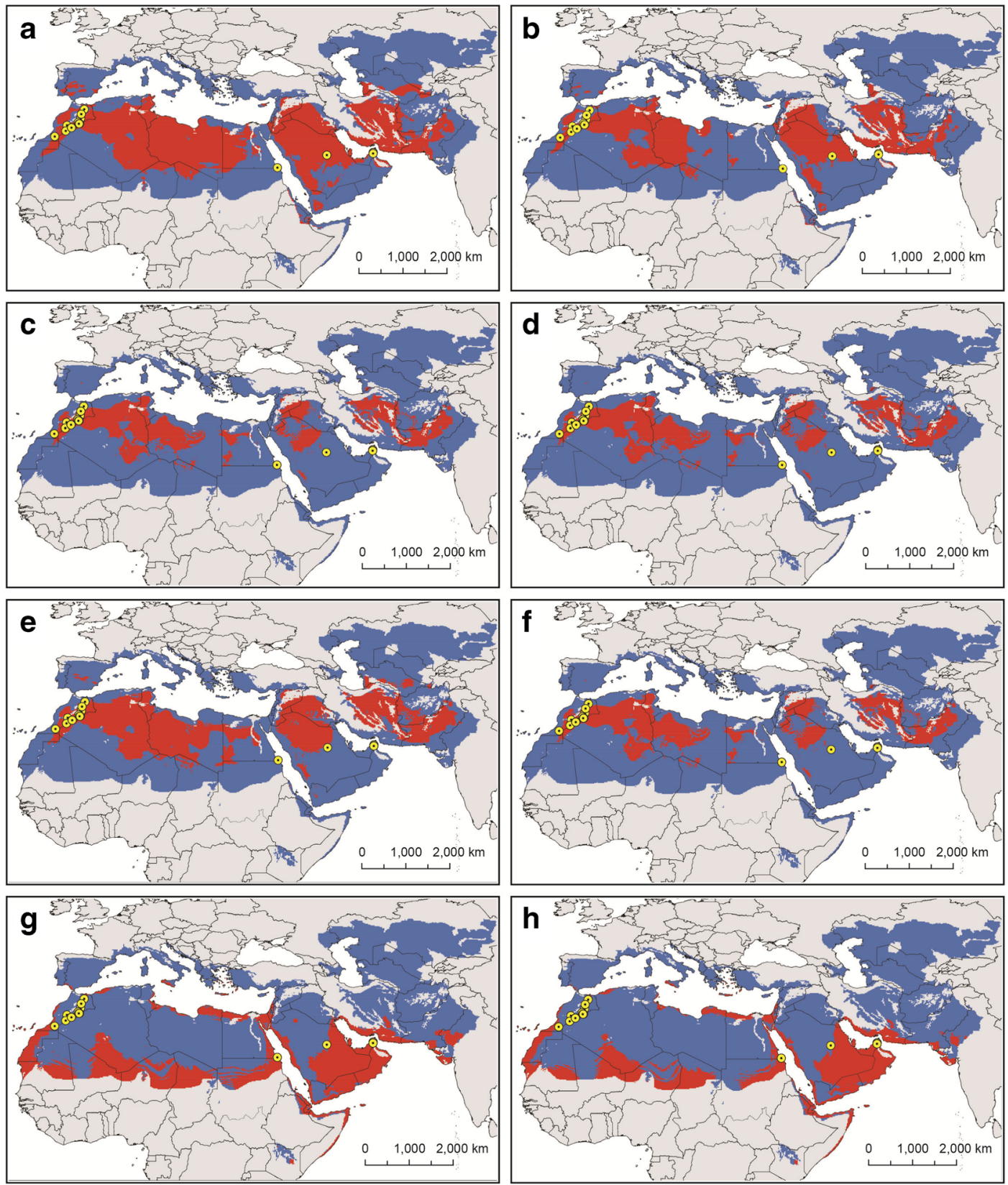

Figure 2. Ecological niche models for Promelitta alboclypeata (Friese) using Maxent with four different sets of occurrences at two thresholds to produce binary predictions (5 and 10\%). First set including all 16 occurrence points at 5 (a) and $10 \%$ (b ) thresholds, second set including a rarefied set of points with all occurrences in the east and an equal number of random west occurrences at 5 (c) and $10 \%$ (d) thresholds, third set including all 12 Moroccan localities at 5 (e) and $10 \%$ (f) thresholds, and fourth set including the four localities in the east at 5 (g) and $10 \%(\mathbf{h})$ thresholds. Occurrence points (yellow dotted circles), geographic extent models ( blue), estimated area (red).

narrow floral preferences. According to Michener (2007), this rare bee is possibly an archaic type as are other bees from the Palearctic deserts. The scarce records for the species are also quite 
scattered, and the recent records from the Arabian Peninsula widen its range beyond the African continent. Despite the reasonably good number of specimens reported by Michez et al. (2007), the number of geographic locations for the species is still quite reduced, and most of them, besides the new records here presented, are from Morocco in the western side of the known distribution. The estimations here presented are an attempt to understand the distribution of the species given the unbalanced representation of geographic information and their scarcity, yet they do correspond nicely with predicted "Sahelian" bee distributions through the Sahelo-Sudanian plant ecoregion (Patiny and Michez 2007). The different sets of occurrences used in the estimations show some stability in terms of the results, at least when using the sets including all occurrences, the rarefied set, and the set of west occurrences. The only contrasting estimation was given by the analysis including only the four east occurrences. This is consistent with observations by Pearson et al. (2007), who mention that model prediction when using subsets of occurrence points is greatly influenced by the particular points included. The same authors also noted that the sample size of localities could be lower than 10 when using Maxent. However, this study involving a low number of occurrence points should be used as launching point to recognize areas to be surveyed as they include the environmental conditions for the species to exist. We take the estimates produced for the occurrence sets including the rarefied and western occurrence points, as a more feasible approach to identify regions to survey for the presence of the bees, as these sets have for the most part similar estimates. Caution should be exercised however as the eastern records are not within the estimate when using this occurrence set. Nonetheless, the disjunct distribution with more than $4150 \mathrm{~km}$ separating the western and eastern populations is dramatic, either representing extreme under sampling in the intervening regions across the Sahara or Sahelian belt, or isolation resulting from extinction across a once larger ancient range ( $P$. alboclypeata, like most melittids, is not a species subject to transport by humans so adventive populations may be ruled out). With all caution taken when interpreting the area estimates here presented, one scenario when comparing the contrasting estimates produced with the eastern occurrences against the other sets is the possibility of two different lineages that have begun to diverge following the extirpation of populations across much of the Saharan region. This scenario would reconcile with one group in the west represented by those specimens found in Morocco and the other by populations found in the east (Sudan, Saudi Arabia, UAE), perhaps representing the initial stages of regional ecological specialization or even cryptic speciation. However, such a scenario must be considered with caution given the morphological uniformity of specimens across the entire range. Our results tend to reveal that there are possible differences in the ecological niche experienced by the western and eastern populations of $P$. alboclypeata and that these differences are in need of further study particularly with greater samples from diverse localities and knowledge of the local biologies of these populations. Although available samples are rare, studies similar to this involving bee species with few known occurrences (e.g., Silva et al. 2013) are advisable even if only a few localities are known, as ecological niche modeling techniques offer a powerful way to understand the feasibility of the presence of environmental conditions, which can promote the discovery of new locality and floral records that will in turn enhance the production of more robust models and refine our understanding of variations in bee ecology as well as hypotheses of species circumscription (Engel 2011; Gonzalez et al. 2013).

\section{ACKNOWLEDGMENTS}

This work was supported by the Deanship of Scientific Research at King Saud University through the research group project No. RGP-189. The authors are also thankful to the Visiting Professor Program at KSU.

\section{La modélisation de la niche écologique de la rare abeille Promelitta alboclypeata, révèle la possibilité d'une différenciation cryptique des populations à travers l'Afrique du Nord et l'Arabie (Hymenoptera: Melittidae)}

Melittidae / modèle / niche écologique / répartition géographique / différenciation écologique 
Die Erstellung eines Modells für die ökologische Nische der seltenen Biene Promelitta alboclypeata gibt Hinweise auf eine kryptische Differenzierung in Nordafrika und Arabien

Melittidae / Promelitta alboclypeata / ökologische Nischen Modelle / ökologische Differenzierung

\section{REFERENCES}

Dathe, H.H. (2009) Order Hymenoptera, superfamily Apoidea: Families Colletidae, Andrenidae, Halictidae, Melittidae, Megachilidae and Apidae. Arthropod Fauna UAE 2, 335-432

Engel, M.S. (2005) Family-group names for bees (Hymenoptera: Apoidea). Am. Mus. Novit. 3476, 1-33

Engel, M.S. (2011) Systematic melittology: Where to from here? Syst. Entomol. 36, 2-15

Engel, M.S., Alqarni, A.S., Hannan, M.A. (2013) A preliminary list of bee genera in the Kingdom of Saudi Arabia (Hymenoptera: Apoidea). J. Saudi Soc. Agric. Sci. 12, 85-89

Gonzalez, V.H., Griswold, T., Engel, M.S. (2013) Obtaining a better taxonomic understanding of native bees: Where do we start? Syst. Entomol. 38 , 645-653

Gonzalez, V.H., Koch, J.B., Griswold, T. (2010) Anthidium vigintiduopunctatum Friese (Hymenoptera: Megachilidae): the elusive "dwarf bee" of the Galápagos Archipelago? Biol. Invasions 12, 2381-2383

Hijmans, R.J., Cameron, S.E., Parra, J.L., Jones, P.G., Jarvis, A. (2005) Very high resolution interpolated climate surfaces for global land areas. Int. J. Climatol. 25, 1965-1978

Hinojosa-Díaz, I.A., Feria-Arroyo, T.P., Engel, M.S. (2009) Potential distribution of orchid bees outside their native range: the cases of Eulaema polychroma (Mocsáry) and Euglossa viridissima Friese in the USA (Hymenoptera: Apidae). Divers. Distrib. 15, 421-428

Olson, D.M., Dinerstein, E., Wikramanayake, E.D., Burgess, N.D., Powell, G.V.N., et al. (2001) Terrestrial ecoregions of the world: a new map of life on Earth. Bioscience 51, 933-938

Michener, C.D. (1981) Classification of the bee family Melittidae, with a review of the species of Meganomiinae. Contrib. Am. Entomol. Inst. 18, 1-135

Michener, C.D. (2007) The Bees of the World, 2nd edn. Johns Hopkins University Press, Baltimore, MD

Michez, D., Else, G.R., Roberts, S.P.M. (2007) Biogeography, floral choices and redescription of Promelitta alboclypeata (Friese 1900) (Hymenoptera: Apoidea: Melittidae). Afr. Entomol. 15, 197-203

Michez, D., Patiny, S., Danforth, B.N. (2009) Phylogeny of the bee family Melittidae (Hymenoptera: Anthophila) based on combined molecular and morphological data. Syst. Entomol. 34, 574-597

Minckley, R.L., Roulston, T.H. (2006) Incidental mutualisms and pollen specialization among bees. In: Waser, N.W., Ollerton, J. (eds.) Plant-Pollinator Interactions: From Specialization to Generalization, pp. 70-98. University of Chicago Press, Chicago

Patiny, S., Michez, D. (2007) Biogeography of bees (Hymenoptera, Apoidea) in Sahara and the Arabian deserts. Insect Syst. Evol. 38, 19-34

Pearson, R.G., Raxworthy, C.J., Nakamura, M., Peterson, A.T. (2007) Predicting species distributions from small numbers of occurrence records: a test case using cryptic geckos in Madagascar. J. Biogeogr. 34, 102-117

Phillips, S.J., Anderson, R.P., Schapire, R.E. (2006) Maximum entropy modeling of species geographic distributions. Ecol. Model. 190, 231-259

Rios, N.E., Bart, H.L. (2010) GEOLocate (Version 3.22) [Computer software]. Belle Chasse, LA: Tulane University Museum of Natural History.

Silva, D.P., Aguiar, A.J.C., Melo, G.A.R., Anjos-Silva, E.J., Marco, D., Jr, P. (2013) Amazonian species within the Cerrado savanna: new records and potential distribution for Aglae caerulea (Apidae: Euglossini). Apidologie 44, 673-683

Sipes, S.D., Wolf, P.G. (2001) Phylogenetic relationships within Diadasia, a group of specialist bees. Mol. Phylogenet. Evol. 19, 144-156 